\title{
Pengaruh Variasi Colling pada Pengelasan GMAW Terhadap Uji Tarik dan Uji Kekerasan pada Baja ST 60
}

\author{
Warso $^{1}$, Trio Nur Wibowo ${ }^{2}$, Yuliyanti Dian Pratiwi ${ }^{3}$ \\ Program Studi Teknik Mesin Sekolah Tinggi Teknik Wiworotomo Purwokerto \\ Email : ${ }^{1}$ warso.januari@gmail.com,,${ }^{2}$ trinw@gmail.com,,${ }^{3}$ dianhilal@gmail.com
}

\begin{abstract}
ABSTRAK
Teknologi industri manufaktur semakin berkembang, dimana semakin pesatnya teknologi tersebut tidak lepas dari bidang pengelasan. Pada proses pengelasan terdapat panas thermal yang digunakan sampai dengan material tersebut mencair, perubahan panas tersebut juga akan menyebabkan perubahan pada struktur, tegangan dan juga deformasi material. Hal ini disebabkan karena semakin banyak unsur karbon tertangkap maka setruktur martensi yang terbentuk juga semakin banyak. Hal tersebut yang menyebabkan peningkatan nilai kekerasan dan nilai kekuatan tarik pada suatu bahan.Tujuan dari penelitian ini adalah untuk mengetahui pengaruh temperatur media pendingin Oli,Air Garam,Air dromus,dan Udara bebas pada pengelasan GMAW terhadap uji tarik baja $S T$ 60. Untuk mengetahui pengaruh temperatur media pendingin Oli,Air Garam,Air dromus,dan Udara bebas pada pengelasan GMAW terhadap uji tarik dan uji kekerasan baja $S T$ 60. Pengujian ini di lakukan dengan beberapa cara pengujian yaitu mengitung Mpa tarik dan HVN kekerasan. Metode penelitian ini menggunakan metode eksperimen Proses pengelasan GMAW menggunakan Variasi pendingin Oli,Air Garam,Air dromus,dan Udara bebas dengan waktu 25 menit dan arus 100 A. Jenis kampuh yang di guanakan adalah kampuh $\mathrm{V}$ dengan sudut $30^{\circ}$.Pengujian yang di lakukan adalah pengujian tarik dan pengujian kekerasan.,nilai Rata-rata Tegangan tarik spesimen.yang tertingi dari Tegangan tarik spesimen pendingin air garam adalah 490.23 Mpa. Nilai rata-rata yang tertinggi dari regangan tarik spesimen udara bebas adalah $35.45 \mathrm{Mpa}$. Nilai Rata-Rata HVN kekerasan spesimen Oli 208.3 HVN,Air garam 231.0 HVN, Air dromus 215.5 HVN, dan Udara bebas $228.0 \mathrm{HVN}$. Dari nilai rata-rata kekerasan HVN nilai tertinggi yang teramati adalah spesimen Air garam sebesar $231.0 \mathrm{HVN}$.
\end{abstract}

Kata kunci : Bahan ST 60 ,pengelasan,pendinginan,uji tarik,uji kekerasan

\begin{abstract}
The technology of the manufacturing industry is developing rapidly, where the rapid development of this technology cannot be separated from the welding field. In the welding process, thermal heat is used until the material melts, the heat change will also cause changes in the structure, stress and also deformation of the material. This is because the more carbon elements are captured, the more martyred structures are formed. This causes an increase in the value of hardness and tensile strength values in the material. The purpose of this study was to determine the effect of the temperature of the cooling medium oil, salt water, water. dromus, and free air in GMAW welding on the tensile test of ST 60 steel. To determine the effect of cooling temperature medium of Oil, Salt Water, Dromus Water, and Free Air on GMAW welding toward the tensile test and hardness test of ST 60 steel. Several means used for testing are calculating the tensile stress Mpa and HVN hardness. This research method used the experimental method. The GMAW welding process variations of coolant were used, such as oil, salt water, dromus water, and free air with a time of 25 minutes and electic current of $100 \mathrm{~A}$. The type of seam used was a V type with angle of $30^{\circ}$. The tests carried out were tensile and hardness test. The highest average value of the tensile stress from the the salt water coolant specimen was $490.23 \mathrm{Mpa}$. The highest average value of the tensile strain from free air specimens was $35.45 \mathrm{Mpa}$. The average value of HVN hardness from Oil specimens was 208.3 HVN, salt water was $231.0 \mathrm{HVN}$, Dromus water was $215.5 \mathrm{HVN}$, and free air was $228.0 \mathrm{HVN}$. From the average value of HVN hardness, the highest value observed was the salt water specimen with $231.0 \mathrm{HVN}$.
\end{abstract}

Keywords: ST 60 material, welding, cooling, tensile test, hardness test 


\section{Pendahuluan}

Teknologi industri manufaktur semakin berkembang, dimana semakin pesatnya teknologi tersebut tidak lepas dari bidang pengelasan, karena pengelasan mempunyai peranan yang cukup penting dalam pembuatan produk. Khususnya pada segi pembangunan konstruksi proses yang dikerjakan tidak lepas dari unsur pengelasan. Pada proses pengelasan terdapat panas thermal yang digunakan sampai dengan material tersebut mencair, perubahan panas tersebut juga akan menyebabkan perubahan pada struktur, tegangan dan juga deformasi material. Perubahan struktur diakibatkan oleh kecepatan pada pendinginan dari panas tertentu menuju suhu normal atau suhu kamar. Jika proses pendinginan kecepatannya naik, maka proses waktu pendinginannya menjadi lambat terhadap suhu kamar. Oleh sebab itu, akan terbentuk suatu struktur butiran yang rapat, pada proses laju pendinginan yang lambat maka akan terbentuk suatu butiran yang rapat sehingga terjadi penurunan pada nilai kekerasan dan nilai kekuatan tariknya.

Proses penelitian ini untuk mengetahui variasi pendingin dengan menggunakan mesin las GMAW ( Gas Metal Arc Welding )sehingga diharapkan mendapatkan struktur matrial yang sesuai dengan kekuatan matrial [1] [2]

\subsection{Las Gas Metal Arc Welding (GMAW)}

Proses pengelasan las GMAW (Gas Metal Arc Welding), menggunakan suatu kawat dimana kawat tersebut berupa gulungan sehingga secara terusmenerus pengelasan tidak akan putus, kawat tersebut dihubungkan ke pemegang elektroda atau yang disebut dengan holder. Pengelasan GMAW dilindungi oleh gas umunya menggunakan $\mathrm{CO}_{2}$ ataupun Argon, perlindungan dihasilkan dari campuran gas yang diberikan dari luar pengelasan. Pada gambar dibawah ditunjukan skema pada pengelasan GMAW.

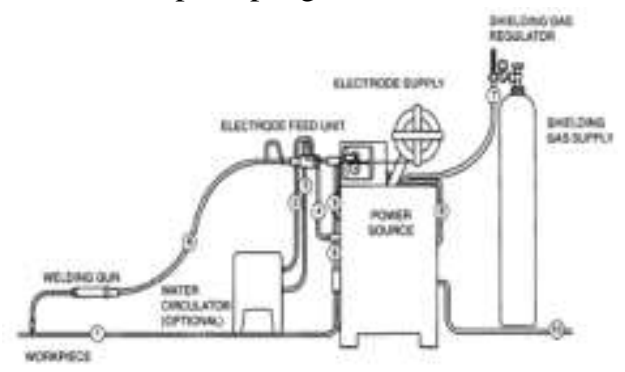

Gambar 1. Skema pengelasan GMAW.

Mesin las GMAW (Gas Metal Arc Welding) yang sering digunakan biasanya mempunyai arus 250 amper, dan dilengkapi pula dengan penggulung kawat, sistem pendingin sampai dengan sistem kontrol arus. Las GMAW merupakan bertegangan stabil berarus DC, tenaga yang dihasilkanpun relatif bisa berubah-rubah tergantung dari panjang busur kawat yang digunakan, panjang busur ini adalah jarak antar holder dengan benda kerja [3]. Panjang busur ini bisa di atur sesuai keinginan operator atau welder dengan menaikan atau menurunkan kecepatan kawat elektroda. Pada pengelasan baja karbon dan sebagian paduan baja karbon rendah perlu diperhatikan campuran pada gas pelindung yaitu $25 \% \quad \mathrm{CO}_{2}$ dan $75 \%$ argon, namun lebih dianjurkan menggunakan $100 \%$ gas $\mathrm{CO}_{2}$. Pada baja paduan rendah disarankan pemakaian campuran gasnya adalah $60-70 \%$ helium, 4-5\% $\mathrm{CO}_{2}$ dan 25$30 \%$ argon [4]. Berikut beberapa fungsi dari gas pelidung adalah :

a. Mengatur penyalaan busur dan perpindahan pada logam

b. Dapat mempengaruhi proses penatrasi, lebar pengelasan dan daerah pengelasan

c. Mempengaruhi kecepatan las

d. Mengaontrol dan mengatur pelelahan material yang berlebih (under cut)

\subsection{Pendinginan}

Proses pendinginan pada logam saat erat pada struktur material yang dihasilkan mesalnya semakin cepat logam yang didinginkan maka material tersebut semakin keras, karena karbon yang dihasilkan lebih banyak dibandingkan proses pendinginan yang lambat. Pendinginan udara laju pendinginnya paling lambat dari pendinginan air garam.dromus.oli ,sehingga pada pengelasan GMAW dengan pendinginan udara mempunyai sifat yang lunak dan mempunyai struktur ferlite dan pearlite yang kasar dibandingkan dengan air garam maupun dromus,oli.

\subsection{Kampuh $\mathbf{V}$}

Perbedaan arus rendah dan tinggi pada kampuh $\mathrm{V}$ sangat mempengaruhi pada segi penetrasi dan kecepatan lelehan material, tembusan atau penetrasi, kemudian pengelasan yang dihasilkan pada kampuh $\mathrm{V}$ dengan arus tinggi dan rendah sangat berpengaruh pada kualitasnya. Oleh karena itu penampang kampuh $\mathrm{V}$ pada material, disarankan menggunakan material dengan ketebalan 6-15 $\mathrm{mm}$ [5].

\subsection{Baja karbon ST 60}

Plat baja pada peneltian ini adalah menggunakan plat baja ST 60 dimana untuk struktur mikronya mempunyai butiran yang halus dan bisa digunakan untuk pengerjaan pada suhu dengan temperatur rendah maupun tinggi. Spesifik dari ST 60 adalah suatu baja dengan kekuatan tarik minimal yaitu $60 \mathrm{~N} / \mathrm{mm}^{2}$ [6].

Baja karbon sedang mempunyai kandungan karbon yaitu dari $0,30 \%$ sampai dengan $0,60 \%$. Dimana baja karbon sedang mempunyai kekuatan dan 
kualitas perlakuan yang lebih tinggi dibandingkan dengan baja karbon rendah. Baja karbon sedang juga bisa dilakukan pengelesan dengan elektroda terindung, dan untuk menghasilkan hasil lasan yang baik maka perlu dilaksanakan pemanasan awal sebelum pengelasan dan dilakukan proses normalizing setelah pengelasan berlangsung [7].

\section{Metodologi Penelitian}

Metode penelitian yang digunakan pada penelitian ini adalah menggunakan metode ekperimen, dimana pengambilan data berasal dari proses pengujian, dalam pengujian ini ada variabel bebas dan variabel terikat. Variabel bebas ini terdiri dari variasi pendinginan yang digunakan seperti oli, air garam, dromus dan udara bebas. Kemudian untuk variable terikatnya adalah kekuatan tarik pada spesimen, posisi pengelasan adalah $3 \mathrm{G}$ dan waktu pendinginannya adalah 25 menit.berikut adalah gambar dimensi spesimen pada uji tarik dan kekerasan menggunakan standar JIZ 22011981.

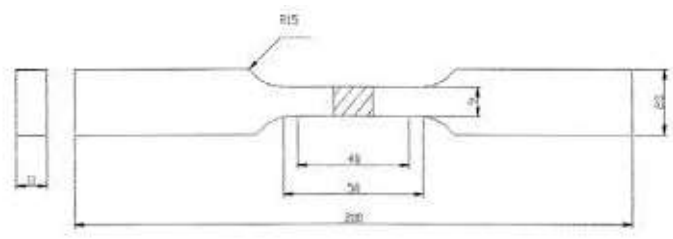

Gambar 2. Dimensi spesimen uji tarik dan kekerasan (JIZ,2201-1981) [8]

\section{Diagram Alir penelitian}

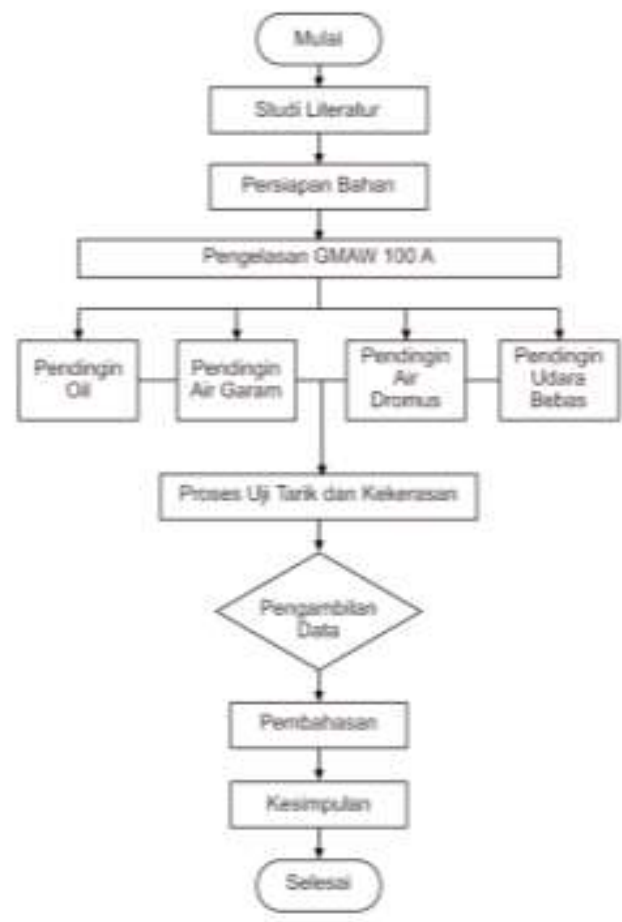

Gambar 3. Diagram alir penelitian

\section{Analisa Data dan Pembahasan}

Setelah dilakukan penelitian, Waktu pendinginan dan variasi pendinginan Oli, Air Garam, Air dromus, Udara bebas.maka diperoleh adanya data yang berupa hasil Pengujian Tarik dan kekerasan Baja ST 60. Untuk penelitian kali ini harus mempunyai data awal spesimen yang akan dilakukan penelitian dan data tersebut sangat penting untuk mempermudah pada saat pengujian.

\subsection{Data Pengujian Tarik}

Pada Hasil Pengujian masing-masing specimen variasi pendinginan Oli,Air garam,Air Dromus,Udara bebas.yang di lakukan pada penelitian ini menggunakan 12 sepesimen setelah dilakukan pengujian tarik dengan menggunakan mesin uji tarik.Maka di dapat beberapa data di antaranya adanaya tegangan tarik dan Regangan, pada hasil pengujian tersebut bisa dilihat pada tebel 1 . berikut ini :

Tabel 1. Hasil Pengujian Tarik

\begin{tabular}{|c|c|c|c|c|c|c|c|}
\hline No & $\begin{array}{c}\text { Pendin } \\
\text { gin }\end{array}$ & $\begin{array}{c}\text { Leba } \\
\mathbf{r} \\
(\mathbf{m m})\end{array}$ & $\begin{array}{c}\text { Teb } \\
\text { al } \\
(\mathbf{m m})\end{array}$ & $\begin{array}{l}P_{\max } \\
(\mathbf{K N})\end{array}$ & $\Delta \mathbf{L}$ & $\begin{array}{c}\text { Tegan } \\
\text { gan }\end{array}$ & $\begin{array}{c}\text { Regan } \\
\text { gan } \\
(\%)\end{array}$ \\
\hline \multirow{3}{*}{1} & Oli & 12.9 & 5.72 & 33.17 & 15.29 & 449.53 & 30.58 \\
\hline & Oli & 13.52 & 5.74 & 35.05 & 16.8 & 451.65 & 33.6 \\
\hline & Oli & 13.04 & 5.72 & 32.46 & 14.42 & 435.19 & 28.84 \\
\hline \multirow{3}{*}{2} & $\begin{array}{l}\text { Air } \\
\text { Garam }\end{array}$ & 12.38 & 5.44 & 34.15 & 11.83 & 507.07 & 23.66 \\
\hline & $\begin{array}{l}\text { Air } \\
\text { Garam }\end{array}$ & 13.9 & 5.36 & 36.23 & 11.37 & 486.28 & 22.74 \\
\hline & $\begin{array}{l}\text { Air } \\
\text { Garam }\end{array}$ & 12.38 & 5.52 & 32.62 & 15.23 & 477.34 & 30.46 \\
\hline \multirow{3}{*}{3} & $\begin{array}{l}\text { Dromu } \\
\mathrm{s}\end{array}$ & 13.26 & 5.6 & 34.13 & 15.29 & 459.63 & 30.58 \\
\hline & $\begin{array}{l}\text { Dromu } \\
\text { s }\end{array}$ & 13.82 & 5.54 & 36.19 & 17.6 & 472.68 & 35.2 \\
\hline & $\begin{array}{l}\text { Dromu } \\
\mathrm{s}\end{array}$ & 13.54 & 5.64 & 34.94 & 17.13 & 457.54 & 34.26 \\
\hline \multirow{3}{*}{4} & $\begin{array}{l}\text { Udara } \\
\text { Bebas }\end{array}$ & 13.78 & 5.64 & 36.24 & 18.34 & 466.29 & 36.68 \\
\hline & $\begin{array}{l}\text { Udara } \\
\text { Bebas }\end{array}$ & 14.04 & 5.42 & 36.17 & 18.7 & 475.32 & 37.4 \\
\hline & $\begin{array}{l}\text { Udara } \\
\text { Bebas }\end{array}$ & 14.88 & 5.62 & 36.11 & 16.14 & 431.81 & 32.28 \\
\hline
\end{tabular}

Perhitungan nilai kekuatan Tegangan Tarik ratarata sepesimen Oli dengan waktu Pendinginan 25 menit dan kuat arus 100 A menggunakan persamaan di dapat hasil sebagai berikut :

$$
\begin{aligned}
\sigma=\frac{F}{A_{\circ}}=\frac{F}{L \times T} & \\
\sigma= & \frac{33,17^{K N}}{12,9 m m \times 5,72 m m} \\
\sigma & =\frac{33,17^{K N}}{73,78 m m^{2}} \\
\sigma & =\frac{0,449,57^{K N}}{m m^{2}} \\
\sigma & =\frac{449,53^{N}}{m m^{2}}
\end{aligned}
$$


Keterangan :

Perhitungan nilai Regangan tarik rata-rata sepesimen Oli dengan Waktu pendinginan 25 menit dan kuat arus 100 A. menggunakan Persamaan di dapat hasil sebagai berikut :

Perhitungan Regangan (panjang).

$$
\varepsilon=\frac{\Delta L}{L^{\circ}} \times 100 \%=\frac{L-L^{\circ}}{L^{\circ}} \times 100 \%
$$

Dimana :

$\varepsilon=$ Engineering strain regangan $(\%)$

$L \circ=$ Panjang mulai dari batang uji (mm)

$L \quad=$ Panjang batang uji yang dibebani $(\mathrm{mm})$

$$
\varepsilon=\frac{15,29}{50 \mathrm{~mm}} \times 100 \%=30,58 \%
$$

Dari data hasil perhitungan Perpanjangan ini nilai regangan adalah $(30,58 \%)$.

3.1.1. Nilai Rata-rata Tegangan dan Regangan

Data hasil pengujian tarik sepesimen variasi pendinginan Oli,Air Garam,Air Dromus,Udara bebas. Dengan waktu 25 menit dan kuat arus 100 A. Maka didapat beberapa data dianntaranya adanya Tegangan tarik dan Regangan. Dari data hasil pengujian bisa dilihat pada Tabel 2. berikut ini :

Tabel 2. Nilai Tegangan tarik

\begin{tabular}{llcccc}
\hline No & Pendingin & $\mathbf{1}$ & $\mathbf{2}$ & $\mathbf{3}$ & $\begin{array}{c}\text { Mpa (Rata- } \\
\text { Rata) }\end{array}$ \\
\hline 1 & Oli & 449.53 & 451.65 & 435.19 & 445.45 \\
2 & Air Garam & 507.07 & 486.28 & 477.34 & 490.23 \\
3 & Air Dromus & 472.68 & 459.63 & 457.54 & 463.28 \\
4 & Udara bebas & 431.81 & 466.29 & 475.32 & 457.8 \\
\hline
\end{tabular}

Dari tabel 2. di ketahui bahwa nilai Tegangan maksimal Pada sepesimen yang diberiperlakuan variasi Pendinginan Oli, air garam, air dromus, udara bebas. dengan waktu 25 menit dan kuat arus $100 \mathrm{~A}$, nilai ratarata pendiginan Oli $(445,45)$, air garam $(490,23)$, air dromus $(463,28)$, udara bebas $(457,8)$. Kemudian di buat Diagram untuk mempermudah pembacaan dan analisa.

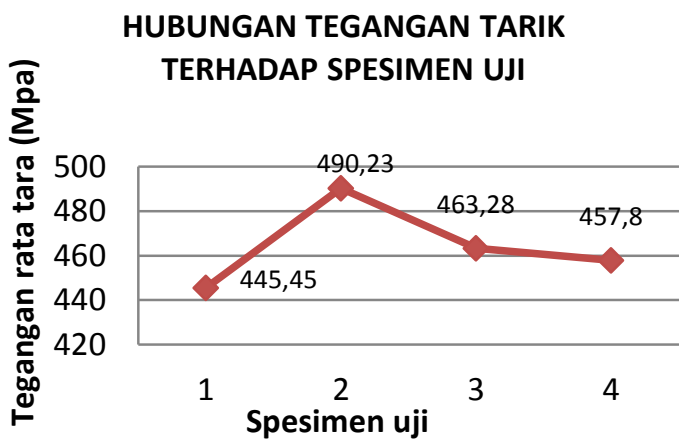

Gambar 4. Grafik Rata-Rata Tegangan tarik ( Mpa)
Data Grafik 4. tersebut menunjukan nilai rata rata tegangan (Mpa) Variasi Pendinginan Oli,Air Garam,Air Dromus,Udara bebas. Dengan waktu 25 menit dan kuatarus $100 \mathrm{~A}$, dari hasil data Grafik tersebut juga menunjukan nilai rata - rata tegangan tertinggi adalah variasi pendinginan air garam dengan nilai (Mpa) sebesar $(490,23)$. Tabel 2. hasil pengujian tarik spesimen variasi pendinginan oli, air garam, air dromus, udara bebas dengan waktu 25 menit dan kuat arus 100 A. Maka didapat beberapa data diantaranya adanya Tegangan tarik dan regangan dari dua data tersebut dapat di cari data hasil dari pengujian tersebut dapat dilihat pada Tabel 3. berikut ini:

Tabel 3. Nilai Regangan Tarik

\begin{tabular}{clcccc}
\hline No & Pendingin & $\mathbf{1}$ & $\begin{array}{c}\text { Spesimen } \\
\mathbf{2}\end{array}$ & $\mathbf{3}$ & $\begin{array}{c}\text { Mpa (Rata- } \\
\text { Rata) }\end{array}$ \\
\hline 1 & Oli & 30.58 & 33.6 & 28.84 & 31 \\
2 & Air Garam & 23.66 & 22.74 & 30.46 & 25.6 \\
3 & Air Dromus & 30.58 & 35.2 & 34.26 & 33.3 \\
4 & Udara bebas & 36.68 & 32.28 & 37.4 & 35.4 \\
\hline
\end{tabular}

Dari tabel 3. diketahui bahwa nilai tegangan maksimal pada spesimen yang di beri perlakuan variasi pendinginan oli, air garam, air dromus, udara bebas. dengan waktu 25 menit dan kuat arus $100 \mathrm{~A}$, nilai ratarata pendiginan oli $(31,00)$, air garam $(25,62)$, air dromus $(33,34)$, udara bebas $(35,45)$. Kemudian di buat Diagram untuk mempermudah pembacaan dan analisa.

\section{HUBUNGAN REGANGAN TERHADAP SPESIMEN UJI}

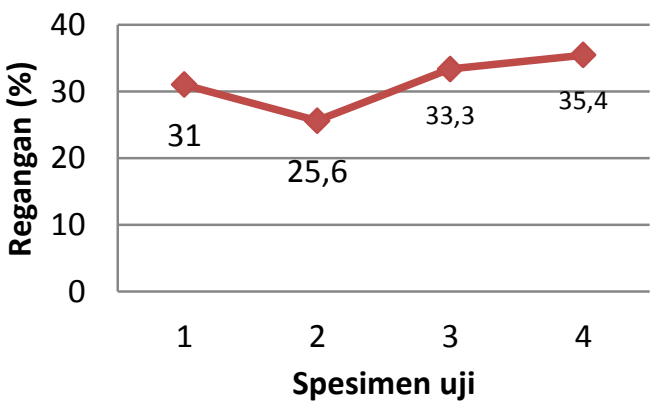

Gambar 5. Grafik Regangan Rata-Rata (\%).

Data Grafik di atas menunjukan nilai rata-rata Regangan (Perpanjangan). Variasi pendinginan oli, air garam, air dromus, udara bebas dengan waktu 25 menit dan kuat arus $100 \mathrm{~A}$, Grafik tersebut menunjukan nilai rata-rata regangan tertinggi adalah variasi Pendinginan udara bebas dengan nilai (perpanjangan) sebesar $(35,45)$.

\subsection{Hasil pengujian kekerasan}

Data hasil pengujian Kekerasan sepesimen variasi pendinginan Oli,Air Garam,Air Dromus,Udara bebas. Dengan waktu 25 menit dan kuat arus 100 A. Maka didapat beberapa data dianntaranya adanya 
Nilai Kekerasan (HVN) data pengujian tersebut dapat dilihat pada Tabel 4. berikut ini:

Tabel 4. Data (HVN) Kekerasan

\begin{tabular}{|c|c|c|c|c|c|}
\hline \multirow{2}{*}{ No } & \multirow{2}{*}{ Pendingin } & \multicolumn{3}{|c|}{ Spesimen } & \multirow{2}{*}{$\begin{array}{c}\text { Mpa (Rata- } \\
\text { Rata) }\end{array}$} \\
\hline & & 1 & 2 & 3 & \\
\hline \multirow{3}{*}{1} & \multirow{3}{*}{ Oli } & 0.59 & 0.59 & 213 & \multirow{3}{*}{208.3} \\
\hline & & 0.6 & 0.6 & 206 & \\
\hline & & 0.6 & 0.6 & 206 & \\
\hline \multirow{3}{*}{2} & \multirow{3}{*}{ Air Garam } & 0.57 & 0.57 & 228.3 & \multirow{3}{*}{231} \\
\hline & & 0.57 & 0.57 & 228.3 & \\
\hline & & 0.56 & 0.56 & 236.5 & \\
\hline \multirow{3}{*}{3} & \multirow{3}{*}{ Air Dromus } & 0.59 & 0.59 & 213 & \multirow{3}{*}{215.5} \\
\hline & & 0.58 & 0.58 & 220.5 & \\
\hline & & 0.59 & 0.59 & 213 & \\
\hline \multirow{3}{*}{4} & \multirow{3}{*}{ Udara bebas } & 0.62 & 0.62 & 192.9 & \multirow{3}{*}{194} \\
\hline & & 0.61 & 0.61 & 199.3 & \\
\hline & & 0.63 & 0.62 & 189.8 & \\
\hline
\end{tabular}

Perhitungan nilai (HVN) rata-rata spesimen oli Dengan waktu pendinginan 25 menit dan kuat arus 100 A menggunakan beban di dapat hasil sebagai berikut :

$$
\begin{aligned}
& \text { Perhitungan Kekerasan (HVN) rata-rata } \\
& \begin{aligned}
\mathrm{HV}=\frac{F}{d^{2}} & \\
\text { Dimana : } & \\
\mathrm{HV} & =\text { Angka Kekerasan Vickers } \\
\mathrm{F} & =\text { Beban }(\text { Kgf }) \\
\mathrm{d} & =\text { diagonal }(\mathrm{mm})
\end{aligned}
\end{aligned}
$$

Tabel 5. Nilai Kekerasan (HVN)

\begin{tabular}{llcccc}
\hline No & Pendingin & \multicolumn{3}{c}{ Spesimen (HVN) } & $\begin{array}{c}\text { Mpa (Rata- } \\
\text { Rata) }\end{array}$ \\
\hline 1 & Oli & 213 & 206 & 206 & 208.3 \\
2 & Air Garam & 228.3 & 228.3 & 236.5 & 231 \\
3 & Air Dromus & 213 & 220.5 & 213 & 215.5 \\
4 & Udara bebas & 295 & 199.3 & 189.8 & 228 \\
\hline
\end{tabular}

Dari tabel 5. diketahui bahwa nilai (HVN) pada spesimen yang diberi perlakuan variasi pendinginan oli, air garam, air dromus, udara bebas dengan waktu 25 menit dan kuat arus $100 \mathrm{~A}$, nilai (HVN) rata-rata pendiginan oli $(208,3)$, air garam $(231,0)$, air dromus $(215,5)$, udara bebas $(228,0)$. Berdasarkan tabel tersebut kemudian di buat diagram untuk mempermudah pembacaan dan analisa.

\section{HUBUNGAN NILAI KEKERASAN TERHADAP SPESIMEN UJ}

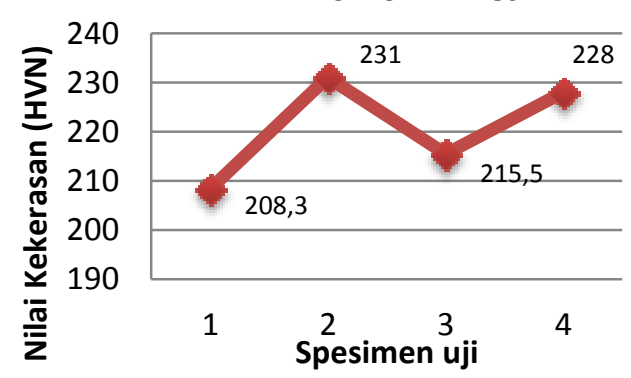

Gambar 6. Grafik Rata-Rata (HVN).
Data Grafik di atas menunjukan nilai (HVN) rata-rata. variasi pendinginan oli, air garam, air dromus, udara bebas dengan waktu 25 menit dan kuat arus $100 \mathrm{~A}$, dari hasil data grafik di atas menunjukan nilai (HVN) rata rata tertinggi adalah variasi pendinginan air garam dengan nilai (HVN) sebesar $(231,0)$.

\section{Kesimpulan}

Setelah mengamati data-data hasil pengujian yang di hasilkan maka dapat di ambil kesimpulan pada pengujian tarik yang terbesar terjadi pada sepesimen yang menggunakan variasi pendinginan air garam yaitu sebesar 490.23 Mpa dan pengujian tarik terendah menggunakan variasi pendingin Oli sebesar 445.45 Mpa..

Pada pengujian kekerasan terdapat perbedaan nilai kekerasan yang di hasilkan menggunakan variasi pendinginan Oli,Air Garam, Dromus,dan Udara bebas. Pengujian menggunakan Mesin uji kekerasan hasil terbesar menggunakan variasi pendinginan air garam dengan menghasilkan nilai Rata-rata sebesar 231 VHN dan hasil terendah pengujian dengan variasi pendinginan oli menghasil kan nilai Rata-rata sebesar 208 VHN,

\section{Daftar Pustaka}

[1] Muhamad Alip, Teori dan Praktek Las. Jakarta: P2LPTK, 1989.

[2] Indra Priyanto, Pengaruh Temperatur Media Pendingin (Air, Collant, Oli) pada Pengelasan GMAW terhadap Struktur Mikro, Kekuatan Tarik dan Kekerasan pada Baja ST 37. Semarang, 2017.

[3] T. O. Harsono Wiryosumarto, Teknologi Pengelasan Logam. Jakarta: PT. Pradnya Paramita, 1996.

[4] G. A. Bintoro, "Dasar-Dasar Pekerjaan Las Jilid 1,” 1st ed., Yogyakarta: Kanisius, 1999.

[5] Widharto, Menuju Juru Las Tingkat Dunia. Jakarta: PT. Pradnya Paramita, 2007.

[6] I. H. P. Susri Mizhar, "Pengaruh Masukan Panas Terhadap Struktur Mikro, Kekerasan Dan Ketangguhan Pada Pengelasan Shield Metal Arc Welding (SMAW) Dari Pipa Baja Diameter 2, 5 Inchi," J. Din., vol. 2, no. 14, pp. 16-22, 2014.

[7] H. Sonawa, Pengaruh untuk Memahami Proses Pengelasan. Bandung: Alfabeta, 2004.

[8] Tata Surdia dan Shinroku Saito, Pengetahuan Bahan Teknik. Jakarta: PT Pradnya Paramita, 2000. 